\title{
Relying on a Single Anuran Species: Feeding Ecology of a Snake Community on Kinkasan Island, Miyagi Prefecture, Japan
}

\author{
AKIRA MORI ${ }^{1 *}$ AND EIKO NAGATA ${ }^{1,2}$ \\ ${ }^{1}$ Department of Zoology, Graduate School of Science, Kyoto University, \\ Sakyo, Kyoto 606-8502, JAPAN \\ ${ }^{2}$ Present address: Sumiyoshi, Osaka 558-0002, JAPAN
}

\begin{abstract}
Feeding habits of snakes on Kinkasan Island, where potential food resources for snakes is limited, was investigated based on field surveys of six years. In total 280 snakes, which consisted of five species (Elaphe quadrivirgata, E. climacophora, Euprepiophis conspicillatus, Rhabdophis tigrinus, and Gloydius blomhoffii), were collected. A total of 168 prey items were recovered from the stomach contents of these snakes. The diet of $\boldsymbol{R}$. tigrinus and G. blomhoffii exclusively consisted of a frog, Rana tagoi, which is the only amphibian species inhabiting Kinkasan Island. Diet of El. quadrivirgata was also predominantly comprised of $R a$. tagoi $(97.7 \%)$. Only endothermic animals were found in the stomach contents of El. climacophora and Eu. conspicillatus. Direct observations of feeding behavior and a broad range of body temperature of El. quadrivirgata indicated that during the breeding season of Ra. tagoi, this snake forages for frogs hiding in crevices of rocks immersed in cold running water of mountain streams. Our study demonstrated that, given the limited prey fauna on Kinkasan Island, two dietary generalists, El. quadrivirgata and G. blomhoffii, and one amphibian specialist, $\boldsymbol{R}$. tigrinus, largely rely on the single frog species as major diet. High exploitation of Ra. tagoi by El. quadrivirgata would be attained by its unique foraging tactics that are characterized by a shuttling movement between hot basking rocks and cold streams for foraging.
\end{abstract}

Key words: Rana tagoi; Island biology; Feeding habits; Geographic variation; Body temperature; Snake community

\section{INTRODUCTION}

Snakes have evolved as successful predators, showing diverse ecological, behavioral, and

* Corresponding author. Tel: +81-75-753-4075; Fax: +81-75-753-4075;

E-mail address: gappa@ethol.zool.kyoto-u.ac.jp morphological adaptations for feeding on various animals (Pough, 1983; Greene, 1997). Some snakes exploit a variety of animal taxa, being referred to as generalist feeders, whereas some others depend on restricted groups of animals, being considered dietary specialists (Mushinsky, 1987). Such feeding adaptation usually leads to food partitioning in a given snake community (Mushinsky, 1987). 
Nonetheless, food partitioning pattern would vary because predominant prey animals of generalist species often change according to the availability of food resources in a local community.

In the main islands of Japan (Hokkaido, Honshu, Shikoku, and Kyushu) and their adjacent small islands, maximally eight species of snakes occur sympatrically. Among them two species, Elaphe quadrivirgata and Gloydius blomhoffii, are considered generalist feeders, exploiting amphibians, reptiles, birds, and mammals, and the remaining six species are more or less dietary specialists (see Mori and Moriguchi, 1988 and Hamanaka et al., 2014 for review). Previous studies demonstrated that E. quadrivirgata predominantly feeds on frogs in populations on main islands, showing a large dietary overlap with a sympatric anuran specialist, Rhabdophis tigrinus (Fukada, 1959; Kadowaki, 1992, 1996; Hirai, 2004; Mori, 2006), but mostly relies on lizards or birds on adjacent small islands where no native frogs are present (Hasegawa and Moriguchi, 1989) or availability of frogs is considered limited (Tanaka and Ota, 2002), showing obvious food partitioning with sympatric snake species. Therefore, food partitioning pattern in the snake communities on the main and adjacent islands of Japan varies, at least partially, due to difference in species composition and abundance of potential prey.

Kinkasan $\left(141^{\circ} 34^{\prime} \mathrm{E}, 38^{\circ} 17.5^{\prime} \mathrm{N}\right)$ is a small island (ca. $10 \mathrm{~km}^{2}$ ) located ca. $700 \mathrm{~m}$ east to Ojika Peninsular, Miyagi Prefecture, Japan. In spite of its close location to the mainland (Honshu) of Japan, the terrestrial vertebrate fauna of Kinkasan Island is relatively poor. Only five species of mammals (two species of insectivores and one species each of rodents, deer, and Macaque monkeys; Asahi et al., 1967; Azuma et al., 1967; Ota, 1967; Miyao, 1973) and seven species of reptiles (five species of snakes and two species of lizards; Nagata and Mori, 2003) have been reported. Particularly, amphibian fauna is very poor: only a ranid frog, Rana tagoi, inhabits this island (Nagata and Mori, 2003) although at least 15 species of amphibians are distributed in the main island part of Miyagi Prefecture (Akiba et al., 2000). Avian fauna is moderately rich (123 species have been recorded), but no densely populated areas, such as a breeding colony of sea birds and aggregation of migratory birds, are present (Izawa and Fujita, 2002a, b). A previous study on the snake community on Kinkasan Island conducted for two years (Kadowaki, 1996) suggests that the two generalist species, E. quadrivirgata and $G$. blomhoffii, as well as the amphibian specialist, $R h$. tigrinus, mostly depend on $R a$. tagoi, although sample size was not explicitly given for E. quadrivirgata. Here, we present further information on food habits of snakes on Kinkasan Island based on six-year surveys as well as body size data. We also examined body temperature of snakes and conducted brief behavioral observations to surmise their foraging tactics characteristic to this island.

\section{Materials and Methods}

Kinkasan is a mountainous island (the highest elevation, $445 \mathrm{~m}$ ), of which vegetation is dominated by sparse forests consisting of a mixture of deciduous broad-leaf and coniferous trees. The main watershed runs along the south-north line at the middle of the island. A network of small streams and brooks is present all over the island, but no permanent stagnant pool is present. Monthly mean air temperature in nearby city, Ishinomaki $\left(141^{\circ} 30.6^{\prime} \mathrm{E}, 38^{\circ} 42.8^{\prime} \mathrm{N}\right)$ in the main island ranges from 0.7 to $23.5 \mathrm{C}$ (Japan Meteorological Agency, 2016).

Field surveys were conducted from May to October 1995, in May and October 1996, in May, June, and October 1997, from May to June 2002 and 2007, and in May 2008. We haphazardly walked along trails and streams over the island basically during the day, but intensive search was made in the western side of the island. We collected snakes by hand or by a snake hook whenever possible. As soon as we captured a snake, we measured the cloa- 
cal body temperature of snakes (BT), air temperature at $1 \mathrm{~m}$ high in shade (AT), and substrate temperature in shade (ST) using a digital thermometer. When snakes were found in water, we measured water temperature as substrate temperature. We brought back snakes to the base cabin, which is located near the center of the island, and measured their snout-vent length (SVL) and body mass (BM). Sex was determined by examining the external shape of the tail base. Stomach contents were examined by palpation and forcedregurgitation. Identified stomach contents were either preserved in formalin or fed back to the snake. The snakes were individually marked by ventral scale clipping and were released at the site of capture basically within 24 hours after collection. Because of time limitation and logistics reasons, some of the above processing were skipped for several snakes, resulting in different sample size among recordings. In several occasions we attempted to make direct behavioral observations of snakes when they seemed to perform foraging activity in streams where $R a$. tagoi was breeding in May and June.

For the analyses of body size measurements only data of initially captured snakes were used. For the analyses of body temperature and diet, data of recaptured individuals as well as initially captured ones were used.

\section{RESUlts}

In total we collected 225 E. quadrivirgata (including recaptured individuals of marked snakes), 31 E. climacophora, two Euprepiophis conspicillatus, $40 \mathrm{Rh}$. tigrinus, and $36 \mathrm{G}$. blomhoffii (Table 1). A total number of marked snakes was 280. Elaphe quadrivirgata was the most predominant species $(68.2 \%)$, followed by $R h$. tigrinus (11.8\%). El. climacophora (10.4\%), and G. blomhoffii (8.9\%). Only two individuals of Eu. conspicillatus were collected. Most of the snakes collected were considered adults (Fig. 1), therefore mean of SVL and BM was calculated using all measured individuals (but excluding measurements for recaptured individuals) (Table 2).

Stomach contents were obtained from $41.9 \%$, $18.2 \%, 50.0 \%, 41.7 \%$, and $26.5 \%$ of El. quadrivirgata, El. climacophora, Eu. conspicillatus, Rh. tigrinus, and G. blomhoffii, respectively (Table 1). A total of 168 prey items were recovered from them, of which $92.3 \%$ was Ra. tagoi (Table 3). All prey items taken from Rhabdophis tigrinus and G. blomhoffii were this frog. Elaphe quadrivirgata also predominantly fed on $R a$. tagoi $(97.7 \%)$. Prey items of the remaining two species, El. climacophora and Eu. conspicillatus, did not contain the frog and consisted of only endothermic animals. Several snakes had multiple frog individuals in their single stomach: two frogs were found from a single stomach of 21 El. quadrivirgata, three Rh. tigrinus, and two G. blomhoffii; three frogs from $13 \mathrm{El}$. quadrivirgata and one Rh. tigrinus; and four frogs from two El. quadrivirgata. We also examined a seasonal variation of the frog dependency of El. quadrivirgata, for which sufficient sample sizewas obtained. Throughout

TABLE 1. A total numbers of snakes collected, marked, and examined for stomach contents. The number of snakes that had stomach contents is also shown. Eq: Elaphe quadrivirgata, Ecli: Elaphe climacophora, Econ: Euprepiophis conspicillatus, Rt: Rhabdophis tigrinus, Gb: Gloydius blomhoffii, M: male, F: female.

\begin{tabular}{|c|c|c|c|c|c|c|c|c|c|c|}
\hline \multirow[b]{2}{*}{ No. of snakes } & \multicolumn{2}{|c|}{$\mathrm{Eq}$} & \multicolumn{2}{|c|}{ Ecli } & \multicolumn{2}{|c|}{ Econ } & \multicolumn{2}{|c|}{ Rt } & \multicolumn{2}{|c|}{$\mathrm{Gb}$} \\
\hline & M & $\mathrm{F}$ & M & $\mathrm{F}$ & M & $\mathrm{F}$ & M & $\mathrm{F}$ & M & $\mathrm{F}$ \\
\hline Total no. collected & 130 & 95 & 15 & 16 & 2 & 0 & 11 & 29 & 12 & 24 \\
\hline No. marked & 98 & 93 & 13 & 16 & 2 & 0 & 10 & 23 & 4 & 21 \\
\hline No. examined for stomach contents & 104 & 75 & 9 & 13 & 2 & 0 & 10 & 14 & 11 & 23 \\
\hline No. having stomach contents & 40 & 35 & 3 & 1 & 1 & 0 & 5 & 5 & 5 & 4 \\
\hline
\end{tabular}


Elaphe quadrivirgata
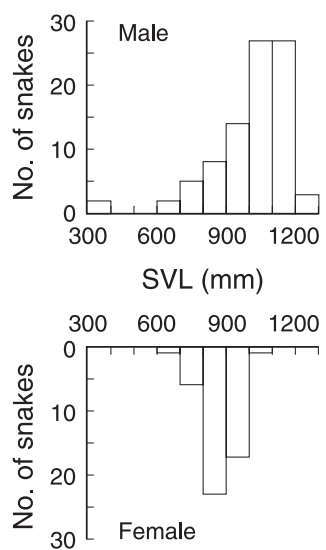

Elaphe climacophora
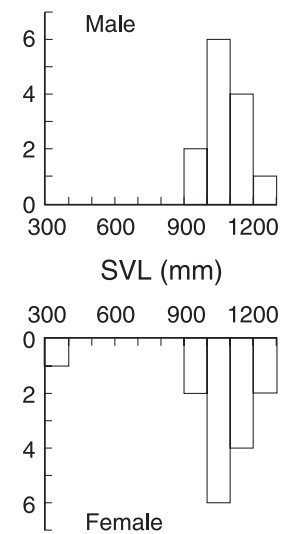

Rhabdophis tigrinus
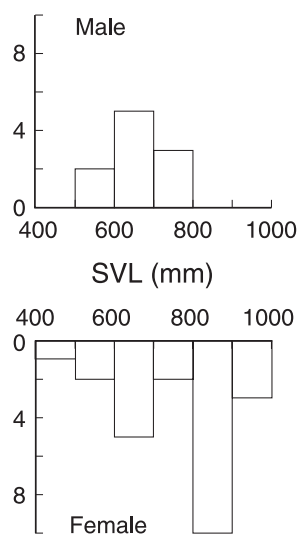

Gloydius blomhoffii

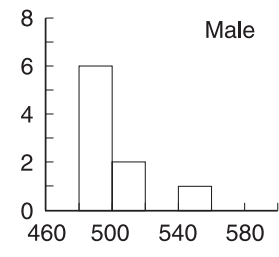

SVL $(\mathrm{mm})$

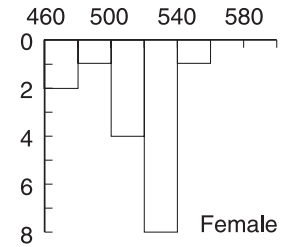

Fig. 1. Distributions of snout-vent length (SVL) of four species of snakes collected on Kinkasan Island. Data of recaptured snakes were excluded. See Table 2 for sample size.

TABLE 2. Mean \pm SE of body size measurements of snakes. Eq: Elaphe quadrivirgata, Ecli: Elaphe climacophora, Econ: Euprepiophis conspicillatus, Rt: Rhabdophis tigrinus, Gb: Gloydius blomhoffii. Sample size and range are shown in parentheses.

\begin{tabular}{lccccc}
\hline & \multicolumn{2}{c}{ Snout-vent length $(\mathrm{mm})$} & & \multicolumn{2}{c}{ Body mass $(\mathrm{g})$} \\
\cline { 2 - 3 } \cline { 5 - 6 } Species & Male & Female & & Male & Female \\
\hline \multirow{2}{*}{ Eq } & $1009.0 \pm 18.0$ & $873.1 \pm 10.7$ & & $350.4 \pm 12.2$ & $232.0 \pm 8.9$ \\
& $(88,303-1263)$ & $(48,670-1010)$ & & $(78,77.2-590)$ & $(48,84-382)$ \\
Ecli & $1092.5 \pm 24.6$ & $1044.6 \pm 55.4$ & & $372.9 \pm 24.3$ & $335.6 \pm 38.9$ \\
& $(13,961-1239)$ & $(15,326-1260)$ & & $(9,268-482)$ & $(14,11-570)$ \\
Econ & 563 & - & & 68.4 & - \\
& $(2,346-780)$ & - & & $(2,12.8-124)$ & - \\
$\mathrm{Rt}$ & $657.8 \pm 19.1$ & $769.3 \pm 27.6$ & & $113.8 \pm 14.6$ & $243.7 \pm 21.3$ \\
& $(10,568-742)$ & $(23,471-970)$ & & $(10,63.5-200)$ & $(22,91-416)$ \\
$\mathrm{Gb}$ & $498.1 \pm 7.4$ & $514.2 \pm 6.2$ & & $100.2 \pm 4.2$ & $136.4 \pm 7.8$ \\
& $(9,480-552)$ & $(16,462-557)$ & & $(6,87-112)$ & $(9,100-180)$ \\
\hline
\end{tabular}

the year medium to high percentages of $E l$. quadrivirgata contained Ra. tagoi as its stomach contents: May, $44.2 \%$ (no. of snakes with Ra. tagoi/no. of snakes examined: 38/86); June, 35\% (14/40); July, 75\% (3/4); August, $35 \%$ (7/20); September, 71.4\% (5/7); October, $36.4 \%(8 / 22)$. Prey items other than frogs were found only in May (two snakes) and September (one snake).

Elaphe quadrivirgata, Rh. tigrinus, and $G$. blomhoffii showed a relatively wide range of body temperature: from 14.1 to $33.3 \mathrm{C}, 14.7$ to $32.5 \mathrm{C}$, and 11.7 to $31.0 \mathrm{C}$, respectively. On the other hand, body temperature range of $E l$. climacophora was relatively narrow, showing 21.3 to $30.4 \mathrm{C}$, although this may be partially due to small sample size. Mean \pm SE of body temperature were $24.5 \pm 0.5 \mathrm{C}, 25.4 \pm 1.3 \mathrm{C}$,

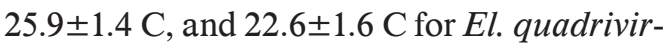
gata, El. climacophora, Rh. tigrinus, and G. 

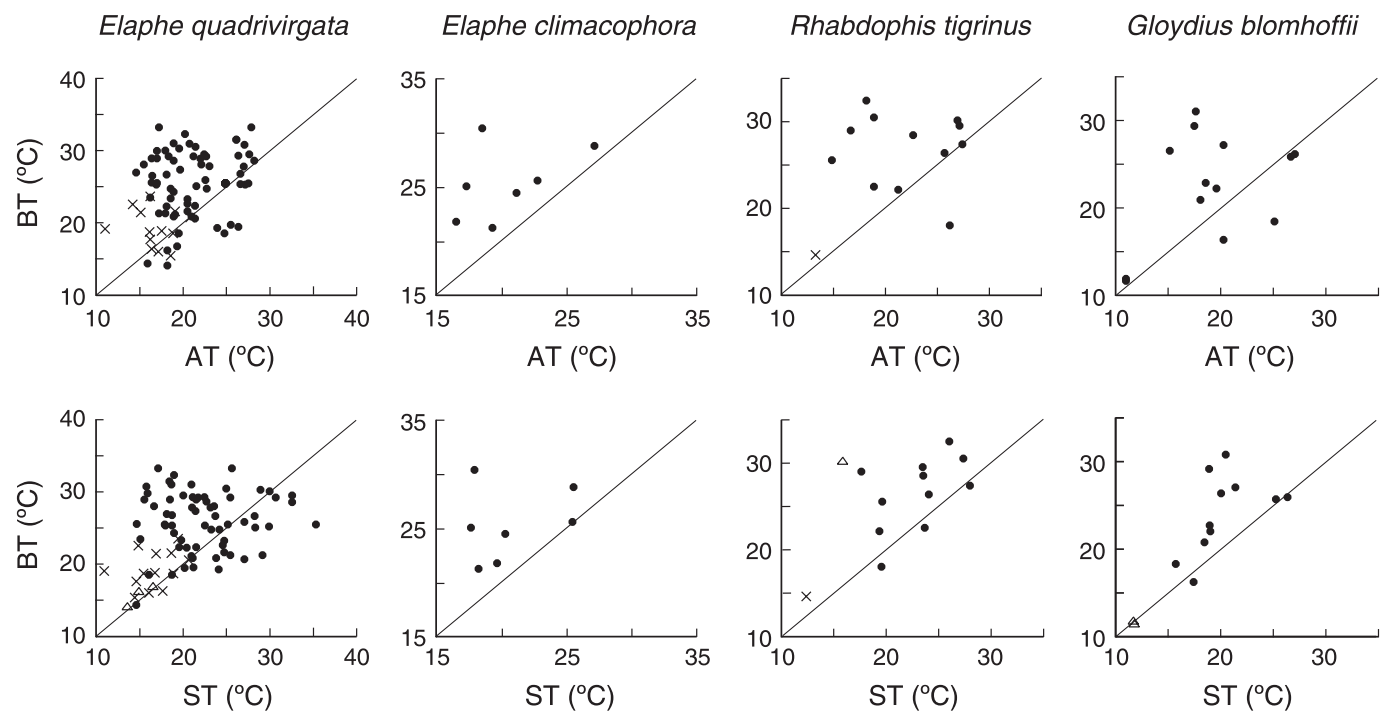

Fig. 2. Relationships between ambient temperature and body temperature in four species of snakes on Kinkasan Island. Except for 13 plots of Elaphe quadrivirgata and one plot of Rhabdophis tigrinus, which were recorded in October (indicated by crosses), temperature data were collected in May or June. Open triangles indicate that water temperature was measured as substrate temperature. The lines where body temperature is equal to ambient temperature are also shown. AT: air temperature, BT: body temperature, ST: substrate temperature.

TABLE 3. Stomach contents of snakes on Kinkasan Island. Numerals in table indicate the individual number of prey items followed by the number of snakes that had stomach contents in parentheses. Eq: Elaphe quadrivirgata, Ecli: Elaphe climacophora, Econ: Euprepiophis conspicillatus, Rt: Rhabdophis tigrinus, Gb: Gloydius blomhoffii.

\begin{tabular}{lccccc}
\hline Prey item & $\mathrm{Eq}$ & Ecli & Econ & $\mathrm{Rt}$ & $\mathrm{Gb}$ \\
\hline Rana tagoi & $127(74)$ & 0 & 0 & $15(10)$ & $11(9)$ \\
Rana tagoi egg mass & $2(2)$ & 0 & 0 & 0 & 0 \\
Takydromus tachydromoides & $1(1)$ & 0 & 0 & 0 & 0 \\
Elaphe quadrivirgata & $1(1)$ & 0 & 0 & 0 & 0 \\
Apodemus argenteus & $1(1)$ & 0 & $2(1)^{*}$ & 0 & 0 \\
Unidentified mammal & 0 & $1(1)$ & 0 & 0 & 0 \\
Unidentified bird & 0 & $1(1)$ & 0 & 0 & 0 \\
Unidentified bird nestling & 0 & $5(1)$ & 0 & 0 & 0 \\
Unidentified bird egg & 0 & $1(1)$ & 0 & 0 & 0 \\
\hline Total & $132(79)$ & $8(4)$ & $2(1)$ & $15(10)$ & $11(9)$ \\
\hline
\end{tabular}

* Based on the same data reported in Nagata and Mori (2003).

blomhoffii, respectively. Temperature data of a single individual of Eu. conspicillatus were 15.8 C (BT), 18.2 C (AT), and 16.7 C (ST). Scatter plots of the relationships between ambient temperature and body temperature showed high variation of body temperature in El. quadrivirgata irrespective of ambient temperature. Nonetheless, maximum body temperature seems to be maintained below $33 \mathrm{C}$ (Fig. 2). 
TABLE 4. Comparison of mean body temperature of five species of snakes between previous and present studies. Eq: Elaphe quadrivirgata, Ecli: Elaphe climacophora, Econ: Euprepiophis conspicillatus, Rt: Rhabdophis tigrinus, Gb: Gloydius blomhoffii.

\begin{tabular}{lcccccc}
\hline Species & $\begin{array}{c}\text { Fukada* } \\
(1985)\end{array}$ & $\begin{array}{c}\text { Fukada* } \\
(1989)\end{array}$ & $\begin{array}{c}\text { Mori } \\
(1994)\end{array}$ & $\begin{array}{c}\text { Kadowaki } \\
(1996)\end{array}$ & $\begin{array}{c}\text { Tanaka and Ota } \\
(2002)\end{array}$ & $\begin{array}{c}\text { Present } \\
\text { study }\end{array}$ \\
\hline Eq & 28.7 & - & - & 28.6 & 27.4 & 24.5 \\
Ecli & - & 27.7 & 24.5 & - & - & 25.4 \\
Econ & - & 24.4 & - & - & - & 15.8 \\
$\mathrm{Rt}$ & - & 26.8 & - & 26.3 & 24.2 & 25.9 \\
$\mathrm{~Gb}$ & - & - & - & 27.8 & - & 22.6 \\
\hline
\end{tabular}

* Conducted in the same study site.

Direct observations of snake behavior in May and June showed that El. quadrivirgata forages for frogs by poking its head into crevices among stones and rocks immersed in running water of streams, where $R a$. tagoi is hiding in the day during its breeding season. Actual feeding events were confirmed several times. We also often observed basking $\mathrm{El}$. quadrivirgata on a rock beside the stream, of which body surface was still wet, throughout the day. No obvious foraging behavior was observed for $R$. tigrinus, E. conspicillatus, and E. climacophora although most of them were collected along or near streams. In most cases, G. blomhoffii was found in an ambushing coiling posture either beside streams or on other habitat such as leaf litter surface of the forest floor.

\section{Discussion}

Our study demonstrated that two generalist species, El. quadrivirgata and G. blomhoffii, and one specialist, Rh. tigrinus, predominantly depend on a single species of frogs, $R a$. tagoi, as their diet, which agrees to the observation by Kadowaki (1996). This high dependency on Ra. tagoi was consistent throughout the year in El. quadrivirgata. No obvious food partitioning was observed among these three species. Although no quantitative survey on the density of prey animals has been made, $R a$. tagoi is very common on Kinkasan Island and can be seen almost all areas of the island, whereas two species of lizards, Plestiodon finitimus and Takydromus tachydromoides, do not seem to be abundant (Mori, personal observations). Abundance of mammals and birds are unknown although a brief survey showed low to moderate density of Apodemus argenteus (Ota, 1967). Kadowaki (1996) compared fatness index of the above three snake species between Kinkasan Island and two populations on the mainland and showed that the index of snakes on Kinkasan Island is larger than or similar to that of mainland populations. These results suggest that the abundance of $R a$. tagoi is quite high on Kinkasan Island to support the populations of the three snake species. On the other hand, two other specialists, El. climacophora and $E u$. conspicillatus, seemed to rely on small mammals and birds. Food partitioning between these two species is unclear although the former may rely more on birds than mammals.

It has been well known that snakes show insular gigantism and dwarfism (Boback, 2003). These phenomena have been demonstrated or suggested for El. quadrivirgata (Hasegawa and Moriguchi, 1989; Tanaka and Ota, 2002; Kuriyama et al., 2011), El. climacophora (Hasegawa and Moriguchi, 1989; Mori, 1994), and Rh. tigrinus (Tanaka and Ota, 2002). Body size changes of snakes on island populations are generally considered to be associated with a diet alteration related to prey type, prey size, and/or the abundance of prey (e.g., Hasegawa and Moriguchi, 1989; 
Boback, 2003; Hasegawa and Mori, 2008). Brief comparisons of mean SVL of snakes on Kinkasan Island with that of snakes from main island populations do not indicate any clear tendency of either gigantism or dwarfism in El. quadrivirgata (mean SVL, 880$1077 \mathrm{~mm}$ for males, $779-864 \mathrm{~mm}$ for females; Fukada, 1992; Kadowaki, 1996; Kuriyama et al., 2011; Tanaka, 2011; Tanaka and Mori, 2011), Rh. tigrinus (mean SVL, 563-607 mm for males, $630-785 \mathrm{~mm}$ for females; Fukada, 1992; Kadowaki, 1996; also see Moriguchi [1985] for frequency distribution of SVL), and G. blomhoffii (mean SVL, 411-461 mm for males, 422-512 mm for females; Fukada, 1992; Kadowaki, 1996; Yomeishu Seizo Co. Ltd., 1999), but suggests possible dwarfism in El. climacophora (mean SVL, $1441 \mathrm{~mm}$ for males, 1289 mm for females; Fukada, 1992; also see Hasegawa and Moriguchi [1989] for insular populations). The absence of dwarfism in the former three species also supports the idea that Ra tagoi is an abundant food resource to foster these snakes on Kinkasan Island.

All species of snakes on Kinkasan Island showed relatively low body temperature compared to that previously reported in other populations (Table 4). In particular, when body temperature is compared between $\mathrm{El}$. quadrivirgata and Rh. tigrinus within the same study site, the former is higher than the latter in the previous studies, which is opposite to the result of our study (Table 4). Lower body temperature in our study may simply reflect the geographic location of Kinkasan Island, which is situated in a cool-temperate climate zone. Another reason, especially for El. quadrivirgata, may be attributable to foraging behavior to exploit frogs hidden in underwater space below rocks of the stream. Direct observations of El. quadrivirgata imply that the high variation of its body temperature is caused by its foraging activity in the stream. Because the water temperature in the stream is usually less than $17 \mathrm{C}$ (see Fig. 2), body temperature of the foraging snakes submerged in the stream would quickly decrease. Basking El. quadrivirgata on a rock beside the stream, of which body surface was still wet, implies that the snake had been submerged in the water before basking (also see the relationship of ST and BT in Fig. 2 that includes many plots of body temperature that are lower than substrate temperature). This shuttling behavior between a hot basking site and a cold stream may have caused the broad range of body temperature and relatively low mean body temperature of El. quadrivirgata.

Our study showed that feeding habit of snakes on Kinkasan Island can be categorized into two types: one that largely depends on frogs and the other that relies on endothermic animals. Although potential prey fauna of snakes on Kinkasan Island is not rich, snakes that are potentially able to utilize amphibians as food do not seem to be suffered from paucity of prey resource and share a single, abundant frog species as major diet. It would be interesting to study how this unique feeding habit affects growth rate, maturation, and longevity of these snakes. Diet of juvenile snakes should be also studied to examine whether any ontogenetic shift occurs in the dependency on the frog. Radio-telemetric study with monitoring body temperature will confirm the unique foraging behavior of $\mathrm{El}$. quadrivirgata and reveal any possible differences in foraging tactics among the three snake species that rely on the same single frog species.

\section{ACKNOWLEDGMents}

We greatly thank K. Izawa for allowing us to use the field cabin for our research. We also thank S. Barribeau, K. Eto, D. A. Hutchinson, N. Kidera, R. A. Saporito, A. H. Savitzky, and $\mathrm{H}$. Takeuchi for their assistance in the field and N. Nakagawa for his help in obtaining literature. We are grateful to the courtesy of mammal researchers on Kinkasan Island during our stay in the cabin. The field research and collection of animals were conducted under the permissions from Miyagihokubu District Forest Office and Ishinomaki Industrial Promotion Office, respectively. 


\section{Literature Cited}

Akiba, Y., Koyama, H., Takahashi, O., and TAKAhashi, Y. 2000. Amphibians and Reptiles of Miyagi Prefecture. Miyagino Yasei Dobutsu Kenkyukai [Wild Animal Research Association of Miyagino], Sendai.

Asahi, M., Azuma, S., Ito, T., Kawai, M., AND HAYASHI, K. 1967. Survey on large mammals of Kinkasan Island, Miyagi Prefecture, 1966Shika deer-. JIBP-CT-S Research Report of 1966: 189-196.

Azuma, S., Hayashi, K., and Kawai, M. 1967. Survey on large mammals of Kinkasan Island, Miyagi Prefecture, 1966-Macaque monkey-. JIBP-CT-S Research Report of 1966: 197203.

Bоваск, S. M. 2003. Body size evolution in snakes: Evidence from island populations. Copeia 2003: 81-94.

FukADA, H. 1959. Biological studies on the snakes. V. Food habits in the fields. Bulletin of the Kyoto Gakugei University, B 14: 22-28.

FUKADA, H. 1985. Body temperatures of snakes in the fields. 1. Elaphe quadrivirgata. Japanese Journal of Herpetology 11: 25-32.

FuKADA, H. 1989. Body temperatures of snakes in the fields. 2. Rhabdophis tigrinus, Elaphe climacophora, Amphiesma vibakari, and Elaphe conspicillata. Japanese Journal of Herpetology 13: 29-34.

Fukada, H. 1992. Snake Life History in Kyoto. Impact Shuppankai Co. Ltd., Tokyo.

Greene, H. W. 1997. Snakes. The Evolution of Mystery in Nature. University of California Press, Berkeley.

Hamanaka, K., Mori, A., and Moriguchi, H. 2014. Literature survey on food habit of snakes in Japan: Revisited. Bulletin of the Herpetological Society of Japan 2014: 167-181.

Hasegawa, M. And Mori, A. 2008. Does a gigantic insular snake grow faster or live longer to be gigantic?: Evidence from a long-term field study. South American Journal of Herpetology 3: 145-154.

Hasegawa, M. and Moriguchi, H. 1989. Geographic variation in food habits, body size and life history traits of the snakes on the Izu
Islands. p. 414-432. In: M. Matsui, T. Hikida, and R. C. Goris (eds.), Current Herpetology in East Asia. Herpetological Society of Japan, Kyoto.

HiraI, T. 2004. Dietary shifts of frog eating snakes in response to seasonal changes in prey availability. Journal of Herpetology 38: 455460.

Izawa, K. And Fujita, H. 2002a. Avi-fauna in Kinkazan Island, Miyagi Prefecture. Miyagi University of Education, Annual Reports of Environmental Education 4: 1-8.

Izawa, K. And Fujita, H. 2002b. Avi-fauna in Kinkazan Island, Miyagi PrefectureSupplement-. Miyagi University of Education, Annual Reports of Environmental Education 5: 47-51.

Japan Meteorological Agency, 2016. http:// www.data.jma.go.jp (accessed 17 June 2016)

KADOWAKI, S. 1992. Food resource overlap between the two sympatric Japanese snakes (Elaphe quadrivirgata and Rhabdophis tigri$n u s)$ in the paddy fields. Japanese Journal of Ecology 42: 1-7.

KADOWAKI, S. 1996. Ecology of a Japanese snake community: Resource use patterns of the three sympatric snakes, Rhabdophis tigrinus, Elaphe quadrivirgata and Agkistrodon b. blomhoffii. Bulletin of Tsukuba University Forests 12: 77 148.

Kuriyama, T., Brandley, M. C., Katayama, A., Mori, A., Honda, M., and Hasegawa, M. 2011. A time-calibrated phylogenetic approach to assessing the phylogeography, colonization history and phenotypic evolution of snakes in the Japanese Izu Islands. Journal of Biogeography 38: 259-271.

MiYAO, T. 1973. Small mammals of Kinkasan Island. In: T. Miyao (ed.), Nihon Honyurui Zakki [Miscellaneous Notes of Japanese Mammals]. Shinshu Honyurui Kenkyukai [Mammal Research Association of Shinshu], Matsumoto.

MORI, A. 1994. Ecological and morphological characteristics of the Japanese rat snake, Elaphe climacophora, on Kammuri-jima Island: A possible case of insular gigantism. The Snake 26: $11-18$. 
MoRI, A. 2006. Is headfirst ingestion essential in gape-limited predators? Prey-handling behavior of the anurophagous snake Rhabdophis tigrinus (Colubridae). Canadian Journal of Zoology 84: 954-963.

Mori, A. AND Moriguchi, H. 1988. Food habits of the snakes in Japan: A critical review. The Snake 20: 98-113.

MoRIGUCHI, H. 1985. Body size differences between two populations of Rhabdophis tigrinus. The Snake 17: 140-143.

Mushinsky, H. R. 1987. Foraging ecology. p. 302-334. In: R. A. Seigel, J. T. Collins, and S. S. Novak (eds.), Snakes. Ecology and Evolutionary Biology. Macmillan Publishing Company, New York.

Nagata, E. ANd Mori, A. 2003. A record of Elaphe conspicillata from Kinkazan Island, Miyagi Prefecture. Bulletin of the Herpetological Society of Japan 2003: 74-75.

ОтА, K. 1967. Survey on small mammals of Kinkasan Island, Miyagi Prefecture, 1966. JIBP-CT-S Research Report of 1966: 184188.

Pough, F. H. 1983. Feeding mechanisms, body size, and the ecology and evolution of snakes: Introduction to the symposium. American Zoologist 23: 339-342.

TANAKA, K. 2011. Phenotypic plasticity of body size in an insular population of a snake. Herpetologica 67: 46-57.

TanaKa, K. And Mori, A. 2011. Reproductive characteristics of Elaphe quadrivirgata (Serpentes: Colubridae) from ecologically dissimilar main island and island populations. Journal of Natural History 45: 211-226.

TANAKa, K. And Ota, H. 2002. Natural history of two colubrid snakes, Elaphe quadrivirtata and Rhabdophis tigrinus, on Yakushima Island, southwestern Japan. Amphibia-Reptilia 23: 323-331.

Yomeishu Seizo Co., Ltd. Central Research LABORATORIES. 1999. Ecology and Artificial Propagation of the Mamushi. Central Research Laboratories, Yomeishu Seizo Co. Ltd., Minowamachi.

Accepted: 1 July 2016 